\title{
PINTURAS RUPESTRES Y TECNOLOGÍA DEL COLOR EN EL EXTREMO SUR DE CHILE
}

MARCELA A. SEPÚLVEDA R."

\section{RESUMEN}

Se presentan los antecedentes existentes sobre pinturas rupestres del extremo austral de Chile. La revisión pone en evidencia la escasez de estudios sistemáticos, la falta de investigaciones recientes que permitan abordar nuevas problemáticas de estudio y su poca consideración en la comprensión de los modos de vida de las poblaciones de esta porción meridional del continente. Se resumen brevemente los principales resultados obtenidos del análisis físico-químico elemental de varias muestras de pinturas rupestres, lo que nos permite discutir una parte de la dimensión tecnológica ligada a la producción de materias colorantes. La variedad y diversidad de recetas empleadas para la producción de las manifestaciones rupestres, e inferidas a partir de estos resultados, ponen de manifiesto la necesidad de ampliar y multiplicar los análisis. Estudios más avanzados podrían, en efecto, permitir abordar de formas más sistemática el estudio de la tecnología del color en el extremo austral de Chile.

PALABRAS CLAVE: Pinturas rupestres, análisis físico- químicos, tecnología del color, Extremo sur de Chile.

\section{ROCK ART PAINTING AND COLOR TECHNOLOGY IN SOUTHERN MOST SOUTH CHILE}

\begin{abstract}
Existing background information on rock art paintings of southernmost south Chile is presented. This review highlights a shortage in systematic studies, the lack of recent research allowing new approaches to study problems, and poor consideration of the matter in the comprehension of life manners of human population in the southernmost south portion of the continent. The main results of elementary physic-chemical analysis of several samples of cave paintings are summarized. This allows discussing part of the technological dimension tied to color production. The variety and diversity of recipes used for rock art painting production, as inferred from these results, reveal the need of extending and multiplying these analyses. More advanced studies might allow more systematic approaches to the study of color technology in southernmost south Chile.

KEY WORDS: Rock art painting, physical-chemical analysis, technology of color, Southern Chile.

Depto. de Antropología, Universidad de Tarapacá. 18 de Septiembre 2222- Casilla 6D, Arica- Chile. msepulveda@uta.cl/ marcelaasre@gmail.com.
\end{abstract}




\section{INTRODUCCIÓN}

La presencia de pinturas rupestres en el extremo sur del Chile es evidenciada en la década de 1930 por Junius Bird (1993). Posteriormente, estas manifestaciones son descritas por Annette Laming-Emperaire, tras su recorrido por esta región, en un artículo referido al arte rupestre de la porción meridional del continente (1966). Actualmente, y pese a haber transcurrido varias décadas, estas manifestaciones visuales permanecen insuficientemente estudiadas. Por un lado los estilos regionales identificados acorde a los diferentes sectores del extremo sur del país, en las décadas de 1970-1980 (Bate 1970 y 1971; Massone 1981, 1982 y 1985), siguen siendo vigentes y carecen de una revisión crítica. Por otro lado, los antecedentes existentes sobre el tema demuestran que los sitios de Patagonia chilena han recibido escasa atención comparado a otras regiones de Patagonia argentina (Menghin 1952 y 1957; Gradin 1967 y 2001; Casamiquela 1984; Aschero 1996; y más recientemente, Podestá et al. 2005; Podestá et al. 2008; Carden et al. 2009 , entre otros).

Tras más de dos décadas del último trabajo publicado sobre el tema se hacía, por ende, necesario retomar el estudio de las pinturas rupestres del extremo sur de Chile aprovechando, también, la existencia nuevos marcos interpretativos y formas de aproximación (ver por ejemplo Gallardo 2009; Whitley 2005). El estudio de las diversas formas de representación, el análisis de las pinturas en su paisaje, la interpretación de los contextos vinculados a las pinturas, el anclaje cronológico de los diferentes estilos identificados, la relación de las pinturas con aspectos territoriales y la tecnología desarrollada en torno a su producción, entre otros, constituyen diferentes formas de ampliar nuestra comprensión $e$ interpretación de las diferentes manifestaciones artísticas legadas por los grupos que poblaron el extremo sur de Chile.

Además, en este extenso territorio, el estudio de las pinturas rupestres constituye un tema particularmente interesante de abordar, ya que las investigaciones realizadas demuestran que el uso de pintura o de materia colorante fue relevante en los diferentes períodos de la secuencia cronológica regional y para las diferentes tradiciones culturales pretéritas y contemporáneas. La pintura se observa reiteradamente sobre otros soportes y en contextos diferentes a los sitios de pinturas rupestres. Entre otros, destacan el hallazgo de objetos pintados y la presencia abundante de pigmentos o materia colorante contenidos en la estratigrafía de contextos domésticos y funerarios (Legoupil y Prieto 1991; Prieto 1991; Christensen 1997; Massone 2009; Fiore et al. 2005 y 2008; Mansur et al. 2007, entre otros). Cronológicamente, la presencia de pintura se vincula a ocupaciones atribuidas a Fell 1 (Massone 1991; Massone y Prieto 2004), así como a tiempos recientes contemporáneos (Fiore 2004; 2005 y 2006). En estos casos más recientes, relatos etnográficos hacen referencia al uso de pinturas en diversos contextos de la vida cotidiana, destacando su uso en pinturas corporales aplicadas para determinadas ocasiones sociales, para ceremonias ligadas a ritos de paso y funerarios, así como para marcar visualmente y diferenciar roles sociales asumidos en las sociedades patagónicas (Fiore 2004, 2005 y 2006). Pese a que no existen evidencias fehacientes en Patagonia, estudios experimentales en la zona pampeana no permiten descartar que el uso de pigmentos haya estado vinculado al trabajo de cueros (Mansur et al. 2007 y 2009).

Durante los años 2006 y 2007¹, la ejecución de dos nuevos proyectos permitió retomar el estudio de varios sitios de pinturas rupestres de la Provincia de Magallanes, con la finalidad de evidenciar, por un lado, la existencia de pinturas atribuidas a los grupos canoeros diferentes a las de los cazadores del extremo sur; por otro lado, efectuar un diagnóstico arqueológico y de conservación de los sitios de pinturas de las zonas de Bahía Lomas, Pali Aike y sectores asociados. La ejecución de estos proyectos permitió actualizar los registros de los sitios de pintura, muestrear algunas pinturas para su análisis composicional elemental, diagnosticar su estado de conservación, y generar una propuesta metodológica para abordar el estudio de las pinturas rupestres (Gallardo 2009).

En este trabajo nos abocamos, específicamente, a presentar los resultados obtenidos del

1 Proyecto CONADI- Univ. de Magallanes, año 2006, "Estudio prospectivo de pinturas rupestres atribuibles a canoeros en Magallanes, $1^{\circ}$ etapa"; Proyecto CONAMA-Univ. De Magallanes, año 2007, "Análisis y Diagnóstico de una ruta Eco-cultural Bahía Lomas, primera Angostura (Estrecho de Magallanes), Pali Aike y sectores asociados". 
análisis físico-químico elemental de varias muestras de pinturas provenientes de diferentes regiones de la porción meridional de Patagonia chilena. Estos primeros resultados evidencian el manejo de diferentes tipos de mezclas lo que podría vincularse a factores temporales, a su vinculación con tradiciones cazadores terrestres o marítimos, a decisiones estilísticas o simplemente al oportunismo de los artistas. Si bien resulta aún preliminar adentrarnos en estos aspectos, se revela la posibilidad de abordar la dimensión tecnológica vinculada a la producción de materias colorantes por parte de las poblaciones patagónicas. Finalmente, esperamos que estos resultados despierten un mayor interés por realizar nuevas investigaciones que consideren la tecnología del color en el extremo sur de Chile.

\section{ESTUDIOS ACERCA DEL ARTE PINTADO DEL EXTREMO AUSTRAL DE CHILE}

El primer reporte vinculado estrictamente al estudio de sitios de pinturas rupestres de Patagonia chilena es aquel realizado por Anette Laming-Emperaire (1966), tras su largo recorrido por Patagonia Austral. En Tierra del Fuego, la autora no encuentra manifestaciones importantes, sólo una cueva cerca del retén de Primavera la cual, en 1961, acababa de ser alterada por un terremoto. En la parte continental, en cambio, en las pampas localizadas al norte del Estrecho de Magallanes, pese a no haber realizado un reconocimiento exhaustivo, la autora menciona la existencia de pinturas relativamente numerosas (en un alero del valle del río Chico, en Cueva Fell, en la cueva Oosin Aike cerca del Río Chico, en cuevas cerca de Laguna Sota y en Cañadon La Leona; Figura 1). En estos sitios, identifica distintos tipos de figuras distinguiendo, por ejemplo, una mano en el alero de río chico, vestigios no muy definidos en pintura roja, numerosos motivos geométricos, relevados únicamente para el caso de la cueva de río Chico, además de algunas figuras de animales esquemáticos en colores rojo, amarillo, café y negro. Laming-Emperaire no ahonda en su estudio pues indica que las pinturas no ofrecen un mayor interés estético, destacando su regular estado de conservación. A pesar de esto, la autora tuvo el ingenio de abrir una puerta para quien se interesara más en detalle por el tema, al plantear de acuerdo a sus limitadas observaciones, la presencia de tres probables estilo:
1) uno asociado a la presencia de la mano (hallado, por ella en el sector de Río Chico), vinculables a estilos ya conocidos para zonas más al norte; 2) un segundo estilo asociado a los motivos geométricos: motivos realizados en pintura roja y trazo grueso o espeso, con líneas curvas y rectas; hallados en forma aislado o en forma compacta para formar figuras de hasta 40 y $60 \mathrm{~cm}$ de altura; finalmente, 3) un tercer estilo vinculado quizás, a las representaciones de figuras humanas y animales, como las encontradas en Cueva La Leona (1966: 496-497).

El primer estudio sistemático acerca de estas pinturas sería desarrollado ulteriormente por Felipe Bate (1970 y 1971). Para este investigador era imprescindible realizar y concretizar investigaciones de este tipo como complemento a los análisis efectuados, hasta entonces, sobre otros indicadores arqueológicos. Al postular la cultura como la configuración integral de todos los diferentes aspectos de la ideología y actividad de un grupo social que se reflejan en mayor o menor grado en la transformación material del medio ambiente que el grupo realiza (Bate 1970:1), se hacía necesario integrar los análisis de arte rupestre para lograr una visión más sintética y completa de la prehistoria del cono sur del continente. Según él, el arte rupestre proveería información igualmente muy valiosa acerca, por ejemplo, de la dispersión geográfica de sus autores, las formas de organización y relaciones sociales de los grupos culturales diferentes, o sobre el sentido de las actividades mágicas.

En su primera campaña Bate recorre sitios de las Provincias de Aysén y de Magallanes (1963). En esta última, identifica cinco sitios con pinturas rupestres: Cueva de la Leona (o Cañadón La Leona), Morro chico, Ush Aike (u Oosin Aike), Cueva Fell y Río Chico-1, estos tres últimos ubicados en el sector de Río Chico (Figura 1). Con estos registros Bate recalca una mayor importancia de este tipo de manifestaciones que la planteada por Anette Laming- Emperaire. Sin embargo, el principal aporte de este nuevo trabajo fue distinguir la presencia de distintos estilos de signos, siguiendo la nomenclatura de Osvaldo Menghin planteada para los sitios argentinos (1957): 1- negativos; 2- pisadas; 3- escenas; 4- signos complicados y simples; 5- grecas; y 6- miniaturas. Estas similitudes permitirían no sólo iniciar la identificación de estilos rupestres para Magallanes, sino vincularlos a los sitios ubicados 
en Patagonia argentina. Sin embargo, pese a las semblanzas, Bate perseguiría la idea de la existencia de sub-variedades estilísticas, por lo menos en una etapa cronológica, para lo que había sido definido y englobado por Menghin (1957) bajo la terminología estilo de símbolos complicados. Es así como Bate identifica la existencia de sub-estilos destacando, entre ellos, el estilo Río Chico. Este se define a través de la presencia de:

punteados, trazos lineales cortos apareados, del ancho de un dedo o más finos, series de trazos lineales en número variable y de longitudes también variables, en un sólo color; series de paralelas relativamente largas de colores alternados, rojo con negro (podrían ser otros colores), de trazos del ancho de un dedo; franjas anchas (3 a $6 \mathrm{~cm}$ ) de rojo bordeado de negro o vice-versa; campos formados por trazos paralelos de diferentes longitudes; series de trazos paralelos atravesados por una perpendicular; figuras antropomorfas muy simples $y$ esquematizadas y ocasionalmente zoomorfas en el mismo estilo; algunos signos simples o concéntricos; círculos radiados; círculos o cuadrados con cruz interior; cuadrados en series; arcos ojivales; signo en forma de herradura; pisadas esquemáticas tipo "rastro de avestruz"; algunos trazos largo y anchos y escasos signos lineales compuestos, probablemente, de inspiración espontánea (Bate 1970:24).

Respecto de los colores empleados en la pintura, Bate recalca el uso del rojo y el negro. Cronológicamente, el investigador asigna el origen de estas manifestaciones a un momento representado por el nivel III de Cueva Fell, por cuanto los niveles superiores de la estratigrafía cubren las pinturas más bajas de esta cueva. Al comparar los materiales de Oosin Aike hallados por Laming-Emperaire y los de Cueva Fell, Bate plantea, además, la posibilidad de establecer un paralelo cronológico entre las manifestaciones de ambos sitios (Bate 1970).

Un año después de la publicación de este primer informe, en 1971, Bate presenta los resultados de su segunda campaña de terreno realizada en 1970. En esta ocasión, el autor identifica nueve sitios nuevos en la Provincia de Magallanes ${ }^{2}$ : Laguna Sofía, Cerro Benítez, Lago Sarmiento 1 y 2 y Gallegos Chico, en el sector de Última Esperanza;

2 Bate reconocería igualmente nuevos sitios para la Provincia de Aysén.
Río Chico 2, 5 y 0 y Cañadón Seco 1, en el sector de Río Chico (Figura 1); aunque reconoce la existencia de otros sitios no descritos dada su escasa cantidad de figuras.

Con estos nuevos descubrimientos, Bate amplía las conclusiones alcanzadas en su anterior investigación. Al descubrir la presencia de un negativo de mano aislado de color blanco amarillento, en asociación con un panel compuesto por signos en forma de "peines", hileras de puntos y líneas paralelas y transversales, el autor logra identificar una mayor dispersión de los negativos, hasta entonces, restringidos a la Provincia de Aysén y a un hallazgo aislado en Oosin Aike. Sin embargo, el mayor aporte de esta nueva campaña radica la definición de varios estilos presentes en la Provincia de Magallanes; pese a no poder fundamentar las causas o razones de sus diferencias. Bate distingue (1971: 39):1. - un estilo ya descrito en el primer informe, denominado "Río Chico", presente en los sitios de Cañadón La Leona y Morro chico. Este se caracteriza por elementos geométricos simples en combinaciones simples (series de paralelas, paralelas "pestañadas o peines", series de punto, paralelas rojo y negro alternado, círculos aislados o concéntricos, algunos radiados o con cruz interior...). Se suman algunos signos antropomorfos y zoomorfos de forma muy esquemática y, por lo general, de tamaño pequeño; 2. - un segundo estilo, presente en Lago Sarmiento 1, definido por la presencia exclusiva de signos antropomorfos, con algunos zoomorfos; por lo general en trazos anchos y con la superficie interior llena de color; finalmente, 3. - un tercer estilo presente en Laguna Sofía, en donde destacan "los motivos relativamente grandes a base de puntos", los "rastros de avestruz", y algunas combinaciones de elementos geométricos simples más variadas y complejas que las de Río Chico.

Con la definición de estos estilos, Bate insinúa la importante diferenciación entre las manifestaciones de la zona de Última Esperanza y el sector de Río Chico (zona de Pali Aike), la cual sería posteriormente retomada por Massone.

A inicios de la década de los 80's, el Instituto de la Patagonia reanuda el estudio de las pinturas rupestres de Patagonia Meridional Chilena (Massone 1981, 1982 y 1985). Este nuevo trabajo buscó sistematizar la información acumulada durante las décadas previas, sumando nuevos hallazgos. Esta investigación tuvo dos objetivos: por un lado, preci- 


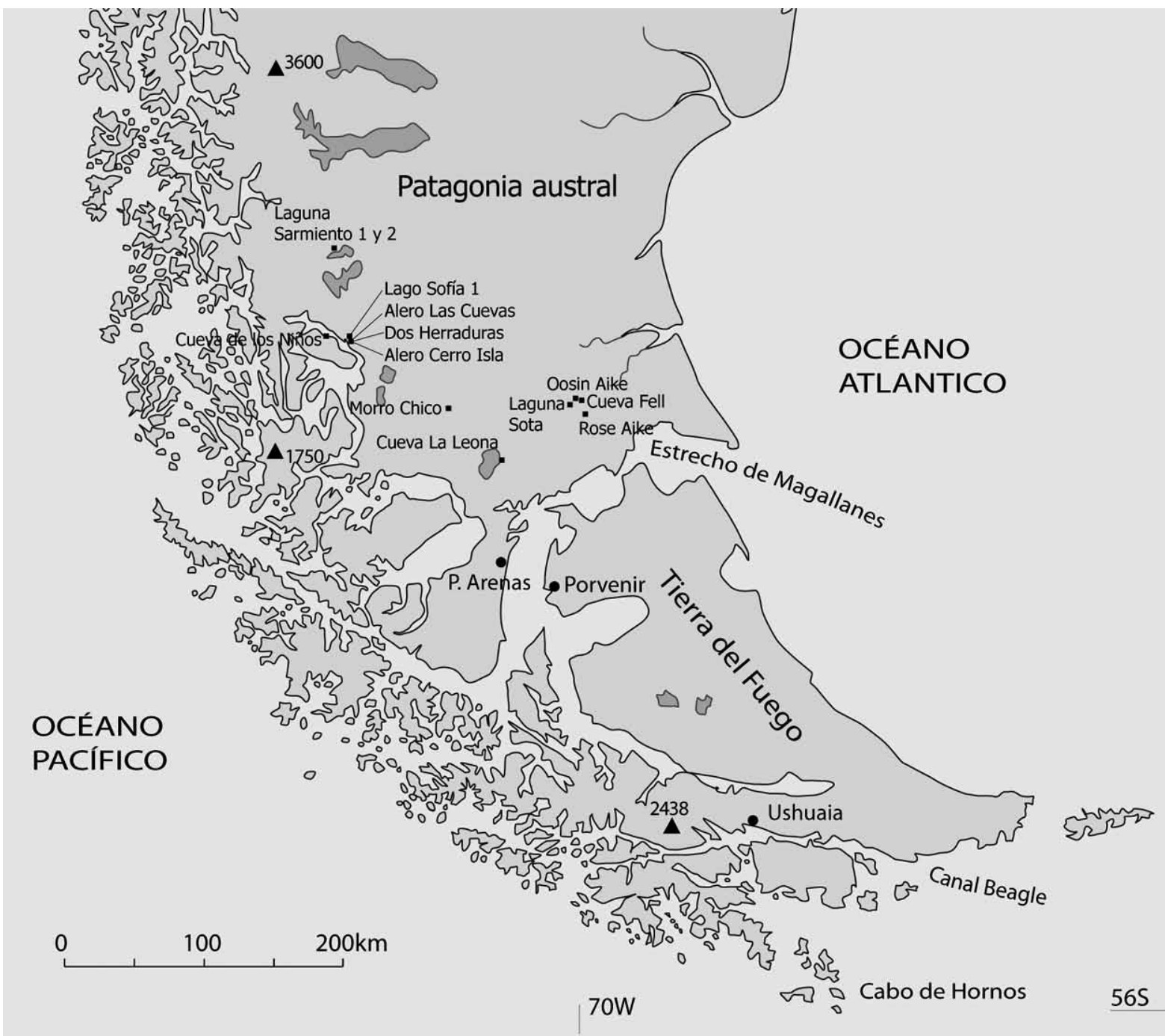

Fig. 1. Mapa de sitios con pinturas rupestres del extremo austral de Chile.

sar las variaciones estilísticas definidas previamente por Felipe Bate; por otro lado, aportar nuevos datos para la asignación temporal de estas manifestaciones pintadas magallánicas.

Los nuevos sitios fueron: Cerro Benítez 2, 3, 4 y 5 , Lago Sofía 2, 3 y 4, en el sector de última Esperanza; y, Laguna Timone 2 y 3, Laguna sota 1, Rosa Aike 2 y 3, Cañadón Seco 2 y 4 y Laguna Los Tábanos 1, en la región esteparia oriental de Pali Aike (Massone 1982 y 1985; Figura 1). Mediante análisis estadísticos aplicados a toda la información compilada, Massone define la existencia de un estilo geométrico prácticamente "puro" en Magallanes; es decir, sin rasgos que indicaran influencias de otros estilos conocidos para Aysén y Patagonia argentina, salvo la presencia de dos manos (un negativo en Oosin Aike y un positivo en Rose Aike 3), más comunes en otras zonas de Patagonia. Este estilo se encuentra en las dos zonas estudiadas, Última Esperanza y Pali Aike; sin embargo, se precisa la existencia de importantes diferencias identificándose dos modalidades o "sub-estilos" estrechamente vinculados (Massone 1982: 91-92). Estas corresponden a las modalidades "Lago Sofía" y "Cerro Benitez" de Última Esperanza y "Río Chico", previamente identificada por Bate. 
La primera modalidad corresponde a lo que es más comúnmente conocido como sub-estilo "Lago Sofía", y se caracteriza por el uso mayoritario de puntos simples o formando figuras más complejas (37,3\% del total de las figuras), además de trazos y figuras lineales, en menor cantidad, y probables figuras zoomorfas esquemáticas dibujadas con gruesos trazos. Al contrario, la segunda modalidad presenta un claro énfasis en el uso de variadas formas de trazos y figuras lineales $(58,1 \%$ del total de las figuras), pudiendo formar ocasionalmente motivos complejos. Igualmente, se reconoce la presencia de algunas figuras antropomorfas y zoomorfas, de formas muy esquemáticas.

Establecida esta distinción, Massone reconoce la enorme dificultad de atribuir una cronología clara a estas dos modalidades pues, además y hasta ese momento, existían muy pocos estudios estratigráficos en sitios con pinturas rupestres. Aún así, considerando los planteamientos previos de Bate (1974) sumados a nuevos antecedentes, Massone se atreve a plantear para la modalidad "Lago Sofía" una atribución cronológica anterior al Período III de Fell, cuyas fechas son 8.180 +/- 135 A.P. y 8.480 +/- 135 A.P. (Massone 1985: 219). Para la modalidad "Río Chico", y a partir de los trabajos realizados en el sitio Río Chico 1, el autor plantea una atribución vinculada al Período IV de Bird, al detectarse a $75 \mathrm{~cm}$ de profundidad la presencia de un fragmento de materia de prima para pintura roja, en asociación con restos líticos, óseos y un fogón fechado en 2.080 +/- 80 A.P. Pese a que, como bien lo precisa el autor, nada pruebe que el pigmento haya sido el utilizado para la confección de las pinturas rupestres, la recurrencia de contextos arqueológicos de los Períodos IV y $\mathrm{V}$ en varios sitios de pinturas (Laguna Timone 2, Laguna Sota 1, Rose Aike 3 y Laguna Los Tábanos 1) contribuye fuertemente a apoyar esta atribución cronológica relativa (Massone 1985: 219).

Tras dos décadas y recientemente, investigaciones espeleológicas desarrolladas en los archipiélagos del extremo sur permitieron descubrir un hallazgo particularmente destacable. Se trata de una gran cueva con pinturas rupestres en el archipiélago Isla Madre de Dios (Centre Terre 2006; Jaillet 2009). Las representaciones son de colores rojo, definido como ocre por los autores, y negro elaborado a partir de carbón de madera.
Este descubrimiento resulta particularmente inédito ya que corresponde a la primera evidencia de arte rupestre en la zona de archipiélagos, y a las primeras pinturas atribuibles a poblaciones canoeras. Sin embargo, estas pinturas no constituyen aún el objeto de un estudio sistemático.

Pese a los avances sostenidos y clarificadores obtenidos entre la década 1960, y más precisamente desde 1980, la investigación acerca de las pinturas rupestres de Patagonia chilena se ha hecho escasa. No obstante, en las últimas décadas, diferentes proyectos dan cuenta del hallazgo de nuevos sitios, aunque éstos se concentran en la porción septentrional de Patagonia chilena (Reyes y Mena, comentarios personales 2005 y 2010, respectivamente). Se requiere sistematizar la nueva información disponible, a su vez que abordar problemas específicos en relación a estas manifestaciones ${ }^{3}$. En esta ocasión, resumimos los resultados obtenidos de nuevos proyectos desarrollados entre 2006 y 2007.

\section{NUEVOS ANTECEDENTES SOBRE LAS PINTURAS RUPESTRES DEL EXTREMO AUSTRAL}

Las nuevas campañas de registro efectuadas ocurrieron en Octubre 2006 y Noviembre 2007. Durante estas temporadas de campo se registraron 33 sitios con pinturas rupestres mediante fichas de sitio, de paneles y de pinturas; además, de la elaboración de un diagnóstico de conservación de los sitios (Casanova 2006Ms y 2007Ms). Paralelamente, se extrajeron varias muestras de pinturas rupestres para iniciar su caracterización físico-químico mediante el uso de SEM- EDX. Se trataba, en efecto, de abordar por vez primera una identificación de los elementos empleados sin la destrucción de las muestras a fin de poder multiplicar los análisis, ulteriormente.

\section{Emplazamiento y soportes de las pinturas}

El registro de esta información fue necesario ya que, hasta ahora, no existían datos relativos al emplazamiento específico de las pinturas, así como

3 Quisiéramos mencionar el reciente proyecto FONDECYT 1110556 "Sistematizando la arqueología del Ibañez Medio: ¿sub-sistema cultural o adaptación particular de un sistema más amplio?" adjudicado por Francisco Mena e iniciado en Marzo 2011. 


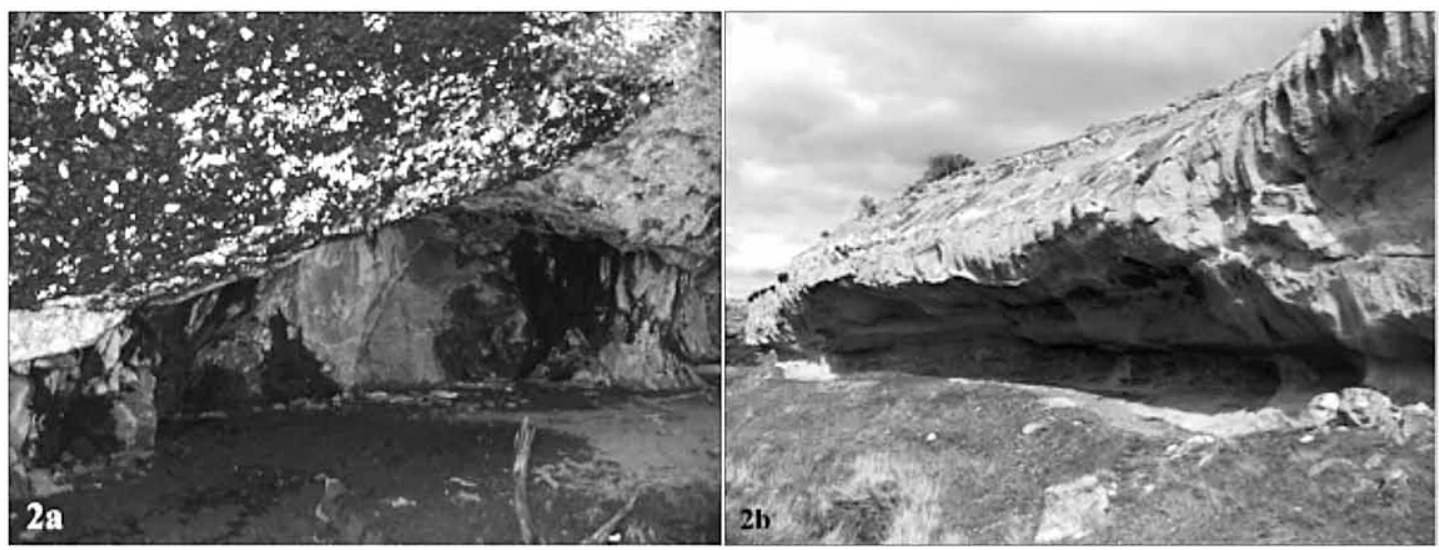

Fig. 2. 2a, Emplazamiento de pinturas al interior de aleros, sitio Cueva 11, sector Cerro Benítez; 2b, Emplazamiento sobre paredes con escasa área de reparo, sitio Cueva de la Leona.

tampoco sobre los soportes empleados. En este caso no se trata de su caracterización petrográfica, sino del estudio del emplazamiento y del soporte, lo cual resulta pertinente en la medida que revelan conductas o elecciones particulares por parte de quienes plasmaron las manifestaciones pintadas sobre las paredes.

Los resultados obtenidos permiten apreciar que, en general, las pinturas se ubican en diferentes emplazamientos. Se registran representaciones al interior de aleros con áreas de reparo de relativo tamaño, como en los casos de Dos Herraduras, Cerro Isla y Cueva 11 de Cerro Benitez (Figura 2a), entre otros. En la mayoría de estos casos, las pinturas se encuentran en cuevas semi-profundas, de entrada relativamente estrecha, dejando las pinturas en la penumbra. Otras pinturas se hallan sobre paredes rocosas de diferente orientación (vertical u horizontal) y con escasa área de reparo como, por ejemplo, en Laguna Sofía, Laguna sarmiento, Cueva Fell y Cueva La Leona (Figura 2b). Consecuentemente, estos emplazamientos afectan directamente la visibilidad de las manifestaciones, no así su conservación. Las pinturas situadas en espacios interiores, en la penumbra, serán difícilmente visibles de lejos; al contrario, pinturas expuestas sobre paredes $\mathrm{O}$ a la entrada de los aleros serán más factibles de ser vistas. Las condiciones de conservación son variables $e$ independientes de su emplazamiento. En efecto, las pinturas situadas en espacios más oscuros no son necesariamente las más preservadas. Estas serán quizás más protegidas frente a posibles agentes externos tales como actos de vandalismo, pero pueden hallarse más expuestas a filtraciones de agua, siendo progresivamente cubiertas por gruesas costras de sales que alteran y afectan directamente su estado de preservación y visibilidad.

En cuanto a soporte, se observa igualmente cierta variabilidad, aunque en la mayoría de los casos corresponden a rocas de origen sedimentario de fina granulometría pero con grande porosidad o bien a rocas de origen volcánica (SERNAGEOMIN 2003). Esta característica permite que, en la actualidad, aún se puedan apreciar numerosas pinturas rupestres en la Región de Magallanes. La capa de pintura aplicada inicialmente ya no existe. No obstante, se observa la impronta de pintura gracias a la materia acumulada en los poros de la roca. Esto nos da cuenta de texturas de pintura lo suficientemente espesas o pastosas, al momento de su aplicación, como para ingresar y quedarse al interior de micro-cavidades o porosidades rocosas.

En cuanto al formato del soporte, se distinguen pinturas realizadas sobre paredes planas $\mathrm{u}$ horizontales (Figura 3a) y representaciones efectuadas aprovechando las caras de clastos (bolones o piedras angulares), de tamaño pequeño (5 cms de largo) a grande (70 cms de largo), insertos dentro de una matriz cenicienta producto de eventos volcánicos violentos (Figura 3b). La elección de estos diferentes formatos de soporte denota decisiones particulares por parte de los artistas quienes escogieron entre diferentes alternativas posibles. El cruce entre la selección y caracterización de estos soportes y el tipo de figura o motivo representado podría darnos ciertas pistas sobre decisiones específicas de índole 

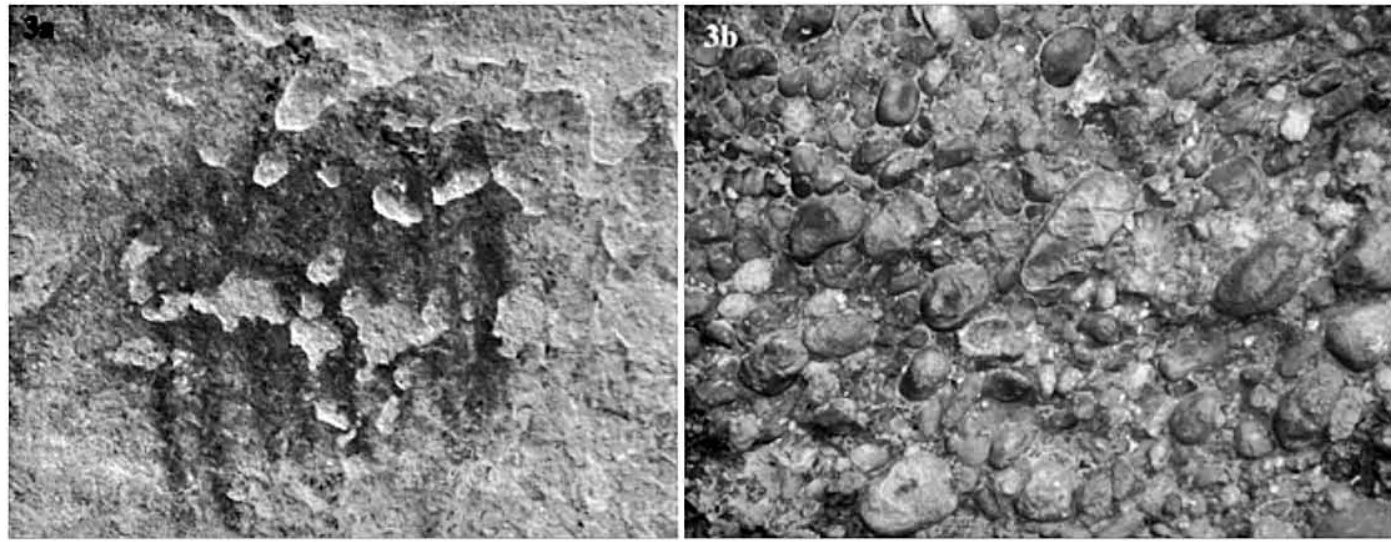

Fig. 3. 3a, soportes planos, sitio Cueva La Leona; 3b, soporte como clastos insertos en matriz cenicienta, sitio La Portería.

estilística, como grupos estilísticos o estilos (sensu Aschero 2001).

\section{Protocolo de muestreo y}

técnicas de análisis

Paralelamente al registro de los sitios, se efectuó un muestreo de pinturas para su análisis físico-químicos y así abordar la temática relativa a la producción de las pinturas, y más ampliamente a su tecnología. Este tipo de análisis ha sido más comúnmente aplicado en Argentina (Iñiguez y Gradin, 1977; Aschero, 1983-1985 y 1988; Wainwright et al., 2000; Boschin et al. 2002; Wainwright et al., 2002;). En Chile, sin embargo, este tipo de aproximación sigue siendo casi inexistente restringiéndose, hasta ahora, a unos análisis efectuados sobre una muestra proveniente de la Cueva Las Guanacas (Mena 1982). Otros análisis físico-químicos fueron realizados sobre objetos coloridos, bloques y pequeños fragmentos de pigmentos provenientes del sitio Bahía Colorada (Christensen 1997).

Las pinturas registradas en Magallanes son generalmente de color rojo, observándose sólo en algunas ocasiones la presencia de pintura blanca (Oosin Aike, Cueva La Leona, Laguna Sarmiento 1) y de negro, correspondiente, en realidad, más a un negro grisáceo (Cueva La Leona). Las muestras realizadas abarcaron todo este espectro de colores para así identificar las materias colorantes empleadas al origen del color. Además, en el caso del rojo se extrajeron muestras de pinturas aplicadas con distintas técnicas (pinturas probablemente aplicadas con brochas o pincel y pinturas aplicadas por pulverizado, directamente con la boca o indirectamente, con el uso de algún elemento como un tubito de hueso o caña -ver Paunero 1992-). En general, el muestreo de pintura fue dificultada por la escasa cantidad de pintura y su adhesión a la roca.

En terreno, cada muestra fue extraída siguiendo un protocolo que se ha venido aplicando hace varios años en el marco de diferentes proyectos (Sepúlveda y Laval 2010). El avance de los métodos de análisis permite que, en la actualidad, una pequeña muestra de pintura sea suficiente para su análisis, logrando extracciones casi invisibles a simple vista.

En el laboratorio, cada muestra es primeramente observada con lupa binocular, obteniendo así datos sobre la morfología del pigmento, la forma global de los granos, la homogeneidad de la muestra, y observaciones de posibles superposiciones de capas de pinturas, entre otros. Posteriormente, se realizan análisis más específicos gracias a un microscopio electrónico de barrido acoplado a un sistema de detección de rayos $\mathrm{X}\left(\mathrm{SEM}-\mathrm{EDX}^{4}\right)$. Este método permite obtener 3 tipos de información: una imagen topográfica de los granos de pigmento, una imagen por contraste químico que nos muestra bajo distintas tonalidades los diferentes elementos químicos presentes (cartografía); y finalmente, un espectro químico con los distintos elementos químicos existentes en la muestra. Esta técnica sólo permite un análisis elemental de la muestra, y no así una identificación de los minerales. Tampoco,

4 Zeiss LEO $1450 \mathrm{VP}$ con espectrómetros EDS: EDAX y WDS: Oxford Inca Wave. 
permite precisar la naturaleza de los elementos orgánicos, si bien detecta la presencia química de carbonos, y su visualización a través de las imágenes obtenidas con el microscopio. Siendo un método no destructivo, las muestras pueden ser reutilizadas y analizadas mediante otras técnicas físico-químicas (Christensen 1997; Fiore et al. 2005; Vásquez et al. 2008; Yacobaccio et al. 2008).

Una pintura puede componerse de un pigmento, entendido como la materia colorante; de una carga (elemento coloro o incoloro, que entre varias cosas puede permitir aumentar la cantidad de pintura obtenida finalmente) y de un posible aglutinante, que puede permite unir los diferentes compuestos de una pintura, o facilita que ésta adhiera mejor sobre un soporte o superficie, entre otros se menciona el uso de agua, aceites vegetales, grasas animales $\mathrm{u}$ otros elementos orgánicos (Petit y Valot 1991). En nuestro trabajo, los análisis realizados se orientaron a la identificación y caracterización de las fracciones inorgánicas, y particularmente al pigmento o materia colorante al origen del color de una pintura.

Las muestras analizadas provienen de 6 sitios: Dos Herraduras, Laguna Sofía 1 y Cueva del Niño, en el sector de Última Esperanza; Laguna Sarmiento 1 , en el sector aledaño a Torres del Paine; Cueva La Leona, cercana a Laguna Blanca; y, Oosin Aike, en el sector de río Chico (Figura 1). En total, se analizaron 13 muestras de pinturas rupestres (Tabla 1). Las muestras conciernen diferentes colores: 8 rojo, 1 blanco, 3 blanco sobre rojo, 1 negro. Adi- cionalmente, se analizó una muestra proveniente de una veta de color rojo ubicada en la parte superior, sobre la ladera, del sitio Oosin Aike. En esta ocasión no fue posible realizar análisis estratigráficos al no contar con elementos para preparar las muestras. De modo alternativo, la muestra fue analizada por su cara anverso (pintura y pátina superficial), así como por su reverso (soporte), lo que permitió precisar los elementos comunes y los distintos. De esta formar se pudo identificar los elementos correspondientes a la pintura, a la roca-soporte y a los depósitos superficiales.

\section{Resultados de los análisis físico-químicos}

Los resultados obtenidos permiten distinguir y caracterizar el soporte. En algunos sitios, este corresponde a un conglomerado conformado por sedimento (en algunos casos cenizas) y clastos de diferentes tamaños. En otros casos se trata claramente de una roca de tipo basalto de mayor y alta dureza. En todas las muestras analizadas, los elementos químicos mayoritarios son el aluminio, el sílice, el magnesio, el potasio y el sodio en proporciones variables.

En varias pinturas se observó la presencia de aglomerados de azufre y calcio (probablemente sulfato de calcio hidratado como yeso), así como carbón (pico anómalo) y calcio solo (probablemente algún carbonato). También, fue factible identificar tanto por espectro como por imagen la presencia de cristales de sales compuestos por sodio y cloro,

Tabla 1. Cuadro resumen de muestras analizadas en el extremo sur de Chile.

\begin{tabular}{|c|c|c|c|}
\hline Sitio & Código muestra & Descripción & Color \\
\hline Dos Herraduras & DH1 & Trazo lineal & Rojo \\
\hline \multirow{2}{*}{$\begin{array}{l}\text { Laguna } \\
\text { Sofía } 1\end{array}$} & LS1-1 & Motivo 5 & Rojo \\
\hline & LS1-2 & Motivo 13 & Rojo \\
\hline \multirow{4}{*}{$\begin{array}{c}\text { Laguna } \\
\text { Sarmiento } 1\end{array}$} & TP1 & Mano en negativo, pintura aplicada por estarcido & Blanco \\
\hline & TP2 & Blanco de mano sobre figura zoomorfa roja & Blanco sobre rojo \\
\hline & TP3 & Zoomorfo & Rojo \\
\hline & TP4 & Zoomorfo & Rojo \\
\hline \multirow{2}{*}{$\begin{array}{l}\text { Cueva de Los } \\
\text { Niños }\end{array}$} & CN2 & Mancha densa en la parte superior del panel & Rojo \\
\hline & CN3 & Pedazo de pared con pintura roja, hallado en el suelo & Rojo \\
\hline $\begin{array}{c}\text { Cueva } \\
\text { La Leona }\end{array}$ & CL1 & Trazo lineal & $\begin{array}{c}\text { Negro intenso tapado por } \\
\text { capa blanquecina-gris }\end{array}$ \\
\hline \multirow{4}{*}{ Osi Aike } & OA1 & Motivo geométrico lineal & Rojo \\
\hline & OA2 & $\begin{array}{c}\text { Piedra del conglomerado pintado con líneas rojas y } \\
\text { puntos blancos }\end{array}$ & Blanco sobre rojo \\
\hline & OA3 & Zoomorfo, posible ave & Blanco sobre rojo \\
\hline & OA4 & Veta de color & Rojo \\
\hline
\end{tabular}




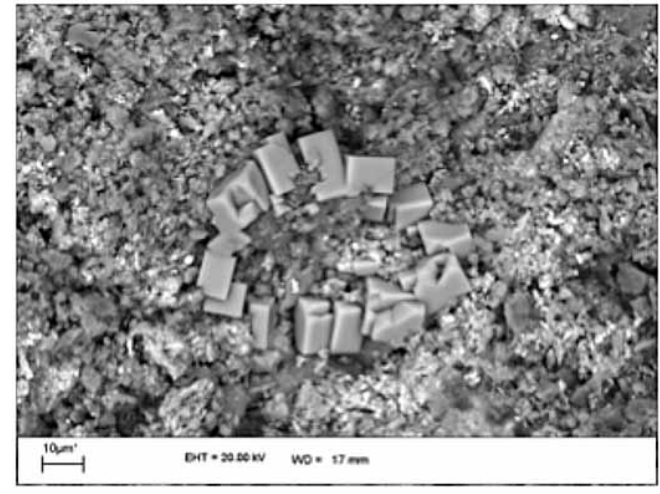

Fig. 4. Sales presentes sobre la superficie de una muestra, sitio Cueva de los Niños.

probablemente cloruro de sodio, comúnmente identificadas como sales (Figura 4). Todos estos elementos diagnosticados en las muestras fueron hallados como depósitos superficiales, y no como parte de la mezcla de pintura. A diferencia de otros autores (Aschero, 1983-1985), descartamos, por ende, que se trate de alguna sustancia usada para preparar el soporte. Más bien, suponemos que se trata de depósitos posteriores formados sobre la pintura, sin duda, en asociación a algún escurrimiento de agua que arrastra elementos oxidados de la roca de soporte; sin embargo, análisis estratigráfico debieran permitirnos precisar dicha observación. La presencia de calcita, de yeso u oxalatos de calcio son comúnmente identificados como depósitos superficiales en los análisis de pinturas rupestres o parietales (Spades y Russ 2005; Watchman 1990; Watchman et al. 2000).

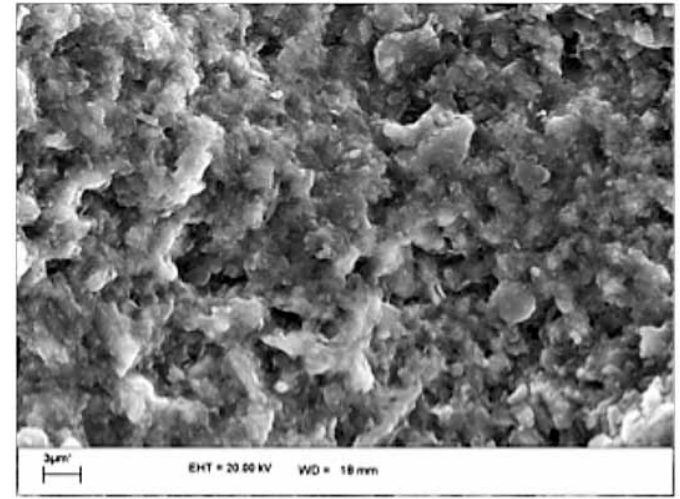

Fig. 5. Estructuras laminares de posibles arcillas, sitio Laguna Sofía 1.

Las pinturas rojas evidencian recurrentemente la presencia de aluminosilicatos, posiblemente arcillas dadas su estructura laminar (Figura 5). A estos elementos se encuentran asociadas cantidades variables de óxidos de hierro. En ninguna muestra fue factible precisar las formas y tamaños de esos óxidos de hierro, a diferencia de otros casos previamente analizados en otras regiones (Sepúlveda et al. 2012), teniendo comúnmente una forma amorfa de muy pequeño tamaño y muy acoplado a las láminas arcillosas. Sin embargo, fue factible reconocer diferentes distribuciones de estos elementos. En algunas muestras se observó una distribución homogénea de los óxidos de hierro. En otros casos, se reconocieron óxidos de hierro agrupados con distribuciones heterogéneas (Figura 6a y 6b). Estas distinciones nos permiten distinguir óxidos de hierro contenidos de forma natural en una arcilla de un elemento agregado de

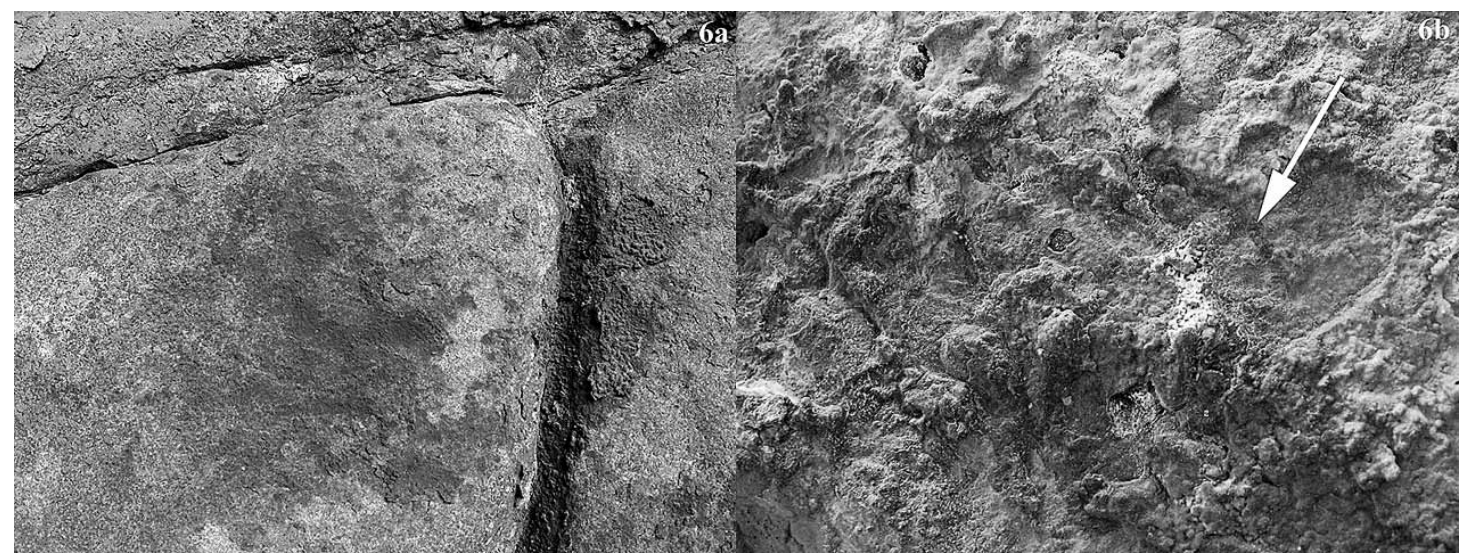

Fig. 6. 6a, pintura roja por estarcido en sitio Cueva de los Niños; 6b, pintura roja aplicada con brocha, sitio Laguna Sarmiento 1 (observar detalle indicado por flecha). 
forma intencional para producir una nueva mezcla. En efecto, una mezcla natural de elementos mostrará una distribución más homogénea de los diferentes elementos presentes. En cambio, en una mezcla artificial la materia colorante es hallada de forma heterogénea. La mezcla se compone de un sustrato o carga (con o sin color natural) a la cual se agrega un pigmento o materia colorante para obtener una diferente tonalidad al color natural de la base o para "colorear" una carga natural incolora.

Se consideró analizar pinturas aplicadas con diferentes técnicas: por estarcido (Cueva de Los Niños; Figura 7b) y con brocha o pincel (Laguna Sarmiento 1; ver detalle en Figura 7b). En términos elementales no fue posible distinguirlas. Sin embargo, pudimos apreciar que en el caso de la Cueva de los Niños se trata de una mezcla bastante heterogénea donde los diferentes elementos aparecen como disociados. Suponemos que se trató de una combinación de elementos composicionales mal mezclados y en un ambiente inicialmente muy acuoso como para permitir su aplicación mediante estarcido.

Adicionalmente, se analizó, aunque de forma preliminar, una veta de color hallada en las cercanías del sitio Oosin Aike, específicamente, en la parte superior de la ladera norte de río Chico. Se trata de una veta que combina elementos tales como el aluminio, sílice, magnesio, sodio, titanio y hierro en relativa baja cantidad. Así, de forma natural se reconocen mezclas de diferentes elementos. Por ello, no es factible determinar que la presencia en algunas muestras de otros elementos, además del material colorante (óxido de hierro, por ejemplo), sea indicador de una mezcla intencional entre algún aluminosilicato y óxidos de hierro. Análisis más detallados con la identificación de elementos trazas, por ejemplo, podría permitir precisar si esta veta fue empleada en la realización de las pinturas de Oosin Aike u otros sitios cercanos (ver, por ejemplo, Popelka- Filcoff 2007).

Los blancos analizados de Oosin Aike corresponden a pinturas realizadas en base a algún aluminosilicato mezclado con fosfato y calcio. Éstos provendrían de restos óseos, como lo demuestran restos de fragmentos observados en algunas muestras (Figura 8). Así, se reconoce el uso de posible hidroxilapatita $\left(\mathrm{Ca}_{5}\left(\mathrm{PO}_{4}\right)_{3} \mathrm{OH}\right)$ compuesto primordial de los huesos. El uso de carbón de hueso para la obtención de coloraciones blancas es mencionado en fuentes etnohistóricas (Manzi 1991). Por lo que este tipo de materia colorante podría usarse tanto para pinturas corporales como para pinturas sobre paredes rocosas.

Estas mezclas particulares, hasta ahora, de Oosin Aike se distinguen de otro tipo de blanco analizado en Laguna Sarmiento 1 (sector de Torres del Paine) donde la pintura corresponde a un aluminosilicato, sin duda, alguna arcilla blanca.

Así, para los blancos se pueden identificar diferentes materias colorantes, y por ende, diferentes mezclas para su obtención. Por ahora, éstas se distinguen por la presencia o la ausencia de elementos óseos. El blanco puede, también, ser aplicado mediante brocha o por estarcido, como en el caso de Laguna Sarmiento 1, delimitando una mano en negativo. En este caso debió tratarse de una mezcla más líquida y de aspecto menos pastosa que lo observado en Oosin Aike.

Un caso de pintura negra, proveniente de Cueva La Leona, entregó un resultado igualmente
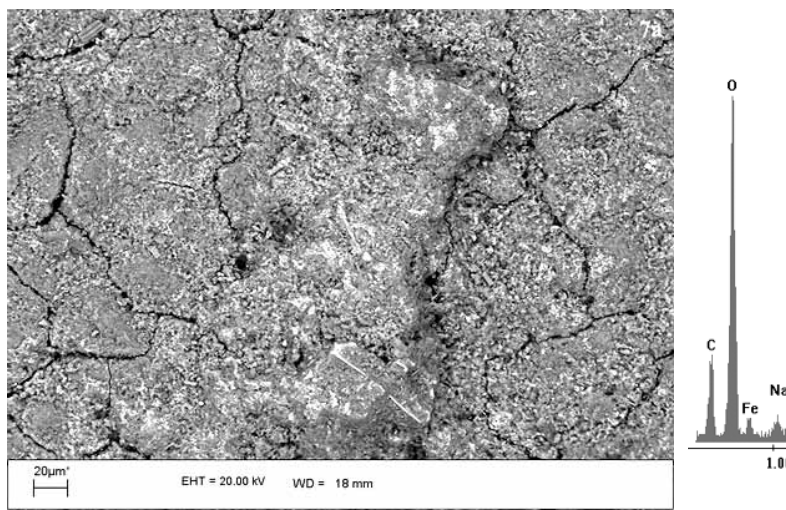

Fig. 7. 7a, imagen de Óxidos de hierro distribuidos de forma heterogénea, sitio Oosin Aike; 7b: espectro de imagen 7a. 


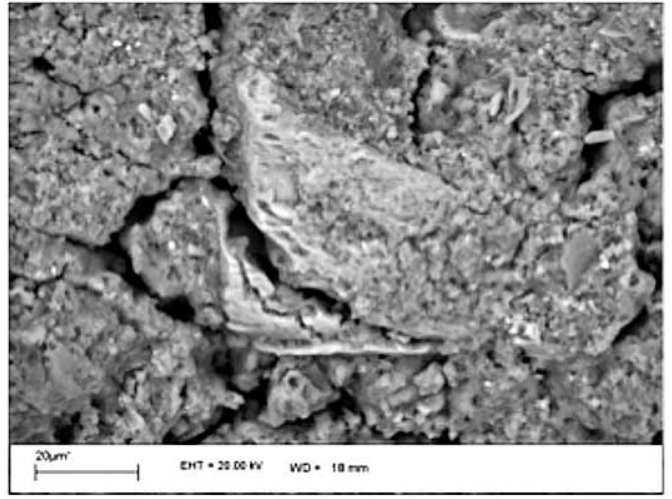

Fig. 8. Presencia de fragmento óseo presente en una muestra de pintura blanca del sitio Oosin Aike.

interesante. Se trata de una pintura compuesta por algún aluminosilicato mezclado a algún componente a base de carbón (Figura 9), el que pudiera corresponder a cenizas de algún elemento quemado, o hueso carbonizado y luego molido. No se observó, en las muestras con carbón, la evidencia del uso de carbón de madera. Tampoco, se observó la presencia de óxidos de manganeso, reconocidos recurrentemente, en otras regiones de Chile, por ejemplo en el norte grande (Sepúlveda et al. 2011a).

Respecto a los ligantes, descartamos el uso de agua de mar. En efecto, no se visualizó la presencia de elementos combinados o formando parte de las mezclas de pintura y que pudieran corresponder a sales presentes, abundantemente, en el agua de mar. Los casos con presencia de sales mostraron partículas depositadas sobre la sección superficial de las muestras, de forma completamente separada de la pintura. Sin embargo, no se descarta el uso de agua dulce, o algún otro tipo de ligante de origen orgánico (grasas animales o resinas vegetales), aún no identificado.

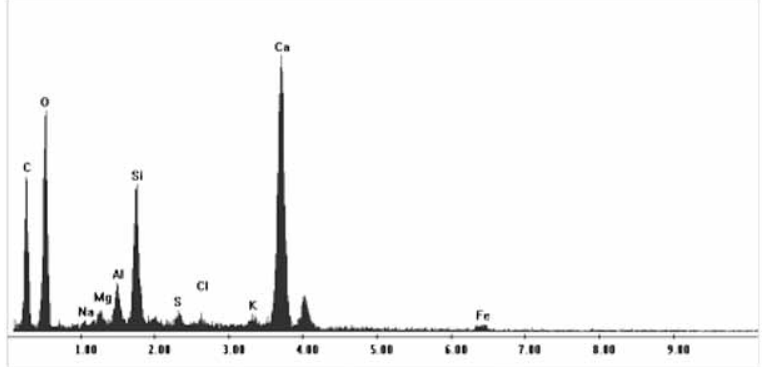

Fig. 9. Espectro de pintura negra proveniente del sitio Cueva La Leona.

\section{Discusión de resultados}

La realización de análisis efectuados por microscopio electrónico de barrido acoplado a un sistema de detección de rayos $\mathrm{X}$ limita en gran medida la realización de mayores inferencias y comparaciones, por ejemplo, a nivel intersitio. Sólo poseemos análisis cualitativos y elementales, no poseyendo la caracterización mineralógica o una cuantificación de los componentes de las muestras que permita una mayor comparación. Sin embargo, se trata de una primera aproximación la cual demuestra que en Patagonia se usaron diferentes materias colorantes y diversas formas de preparación para la producción de pintura.

A partir de nuestro registro y de los análisis, podemos precisar que la conservación de las pinturas se debe en gran medida a la buena adhesión de la pintura al soporte. En muchos casos, lo que se observa en la actualidad podría llamarse una "impronta" de la pintura, pues se trata de la materia presente en los poros la roca. Pensamos que la pintura aplicada debió ser de naturaleza pastosa y de fina granulometría, logrando así una buena compenetración con el soporte. La pintura se habría lavado con el paso del tiempo, siendo finalmente recubierta por una capa fina de carbonato de calcio depositada sobre la superficie de la muestra. Desde entonces, esta concreción actúa como un barniz contribuyendo a la preservación de las pinturas. Además, de carbonatos se identifican también oxalatos (Wainwright et al. 2002), siendo su formación característica de ambientes húmedos y favorable a la formación de ciertos tipos de líquenes.

La naturaleza de la pintura y su posterior lavado en los sitios permiten raramente definir el modo en que esta fue aplicada; sin embargo, algunos trazos nos sugieren que ésta pudo ser aplicada con algún tipo de instrumento (brocha y/o pincel), y sólo en pocos casos se observó la utilización de pintura aplicada desde la boca e intermediado mediante algún objeto alargado ahuecado. Estas distinciones son realizables en terreno únicamente mediante observación macroscópica.

La variedad de pinturas o mezclas al interior de un sitio parece ser un hecho común en los sitios de Patagonia (Boschin et al. 2002; Wainwright et al. 2000 y 2002), y pudiera estar relacionado con el uso de "recursos presentes en 
las inmediaciones de los sitios o en los circuitos de desplazamiento y aprovisionamiento de los grupos cazadores y recolectores" (Boschin et al. 2002). Por ello, la posibilidad de definir circuitos de movilidad y áreas de aprovisionamiento podrían ser profundizados con una mayor cantidad de análisis físico químicos. La caracterización de los materiales empleados en la confección de las pinturas, así como para la identificación de fuentes de materias primas o áreas de aprovisionamiento, son una tarea necesaria no sólo para evidenciar ciertos circuitos de movilidad en relación a este tipo de recursos (Whallon 2006), sino también para precisar el manejo del espacio por parte de los grupos de cazadores recolectores del extremo sur. La comparación iconográfica con otros sitios, y la identificación de relaciones entre ciertos sitios de la zona, debieran permitirnos adentrarnos en la precisión de territorios manejados por los grupos cazadores terrestres o marítimos.

Los resultados obtenidos en este trabajo no nos permiten definir tecnologías a nivel de micro escala, pues resulta aún complejo poder diferenciar mezclas específicas o recetas propias de cada sitio, o de cada grupo estilístico. Sin embargo, la recurrencia en las materias primas u óxidos empleados en las pinturas del extremo sur anuncia ciertos comportamientos tecnológicos relevantes.

\section{HACIA UNA TECNOLOGÍA DEL COLOR...}

El uso de pigmentos o del color, principalmente, el rojo ha sido ampliamente evidenciado en contextos africanos desde el paleolítico inferior. $\mathrm{Su}$ presencia ha sido constantemente abordada en relación al surgimiento de comportamientos simbólicos, o la aparición de símbolos como evidencias de comunicación, sin que exista consenso sobre el momento en que se inician (Barham 1998; Conrad 2005; d'Errico y Nowell 2000; d'Errico et al. 2003; Hovers et al. 2003; Marshack 1981; Petru 2006; Vanhaeren 2005; Williamson 2005; Wreschner 1980). Esta discusión se resume en la necesidad de precisar el uso y función de estos pigmentos, a saber si se encuentran en contextos meramente tecnológicos- económicos o en contextos simbólicos. Es así, como el color en la prehistoria ha sido comúnmente abordado, principalmente, en relación a su contexto de uso (Gage 1999; Jones y Bradley 1999; Jones y MacGregor 2002, entre otros). La utilización de pigmentos en la pintura es más tardía y suele ser más evidente a partir del paleolítico superior (Petru 2006; Taçon 1999).

En América, siguiendo un poco la misma trayectoria, la presencia de pigmentos suele hallarse desde el Paleoindio (Gillespie 2007; Vilhena Vialou et al. 1996; Stafford et al. 2003; Salazar et al. 2010 y 2011); sin embargo, se hace más evidente a partir del arcaico temprano (Massone 1989; Jackson 198990; Massone y Prieto 2004; Santoro, comunicación personal). Hasta ahora, en Chile, no existen evidencias claras que permitan precisar el uso de pigmentos para la producción de pinturas rupestres previo a 5.000 A.P. (Sepúlveda et al. 2011b), si bien en el extremo sur se plantea dicha posibilidad (Bate 1971; Massone 1985). No obstante, no se descarta su uso previo para el trabajo en cuero (sensu Aldenderfer 1990 en Asana, en el sur del Perú) o su aplicación como pintura corporal. Estas utilizaciones de hecho suelen ser ampliamente evidenciadas y comunes para los grupos del extremo sur de Chile en tiempos históricos (Fiore 2004, 2005 y 2006).

El estudio de las pinturas, y más ampliamente del color, debiera entonces ampliar su mirada desde los contextos de uso e intentar abordar su contexto de producción (sensu Fiore 2007). Es decir, que más allá de comprender el significado o la función para la cual se empleó determinado color se trata, también, de reconstruir el proceso productivo involucrado en su obtención. Se trata, como bien ha sido planteado en el estudio de pinturas coloniales, de abordar el color en su dimensión material, más allá de su dimensión simbólica (Siracusano 2008).

Tal como hemos venido desarrollando hace unos años, la finalidad de realizar análisis físicoquímico a las pinturas no se limita a conocer los elementos presentes en ella. Además, del hecho que esta información aún resulte inédita para este tipo de manifestaciones prehispánicas en el extremo sur, nuestra investigación busca revelar y comprender los procesos tecnológicos o tecnología desarrollada en la realización de las pinturas (Sepúlveda 2009).

En efecto, hemos procurado establecer que las pinturas rupestres, al igual que cualquier otra materialidad humana es producto y conjunción de gestos, técnicas, decisiones, conocimientos com- 
binados en determinado ambiente y bajo ciertas condiciones socio-culturales que fijan criterios para la producción de determinado objeto (ver también Aschero 1988; Lemonnier 1986 y 1992; Fiore 2007). Dejando de lado, los problemas de interpretación ligada a los significado de las imágenes rupestres o a la función de las representaciones, o el contexto de uso en el que se insertan -aspectos ampliamente abordados en el estudio del arte rupestre-, pensamos que es necesario indagar en nuevas vías de análisis al resituar este tipo de manifestaciones dentro de la cultura material del hombre del pasado. Las pinturas rupestres son una representación pero son, también, una manifestación visual, una manifestación más del quehacer del hombre, "un artefacto visual" (o tecnofactura, en términos de Aschero 1988).

Las composiciones o recetas (Menu y Walter, 1990) de las pinturas denotan, del mismo modo que para la realización de la cerámica, un cierto conocimiento de los materiales, un saber referido a dónde obtener las materias primas, cómo prepararlas, cómo mezclarlas o combinarlas de modo a obtener una pintura. Sin embargo, su obtención se constituye sólo como una etapa del quehacer de un "artista". La elección de los soportes, de los emplazamientos, las formas a representar, las composiciones de los paneles reflejan otros aspectos como conocimientos, decisiones, técnicas y destrezas necesarios para su producción. Cada receta de pintura incluye indirectamente toda una serie de gestos técnicos o estilísticos específicos y reproducibles (Menu y Walter 1990:12). El pintar implica una compleja "cadena operatoria" de gestos, en cuya sucesión intervienen una serie de reacciones o conocimientos como expresiones de "memorias operatorias" (Leroi-Gourhan en Schlanger 2004). La identificación de estas mezclas podría, entre otros, permitir reestablecer parte de la secuencia de producción involucrada en la realización de las pinturas; sin embargo, pensamos que, más aún, podría permitir resituar "la actividad de producción de pinturas en relación al total de las actividades" de un sitio, de un patrón de asentamiento, de un circuito de movilidad o de intercambio al interior de uno o varios grupos sociales ${ }^{5}$ (cf. Aschero 1988: 109).

Así, la ejecución de un diseño, motivo o composición rupestre implica no sólo determinadas elecciones y/o circulación de ideas, conceptos o conocimientos acerca de cómo realizar las representaciones rupestres en cuanto a su concepción visual y gráfica, sino también en cuanto a su materialización. Por ende, entendemos la tecnología del color como la posibilidad de ampliar nuestra comprensión sobre el fenónemo rupestre a través del estudio de diversos aspectos referidos a su materialidad en un ambiente específico y bajo determinadas condiciones socio-culturales. En este sentido, se trata de considerar de forma complementaria aspectos vinculados a los contextos de uso y de producción en los que se inserta el color, pensando que el extremo sur de Chile resulta ser un espacio particularmente pertinente para este tipo de aproximación dada la variedad de información arqueológica, y etnográfica existente, y el uso aún reciente de este tipo de materialidad.

\section{AGRADECIMIENTOS}

Trabajo iniciado el año 2007 y finalizado en el marco del proyecto FONDECYT 1100354 y estancia Post-Doctoral en Francia financiada por Beca Hermés, Maison des Sciences de l'Homme (Noviembre 2010- Mayo 2011). Quisiera agradecer a Alfredo Prieto por invitarme a participar de estas experiencias sureñas, y a quienes me acompañaran en estas aventuras Gabriel Bahamondes y Pedro Cárdenas. Igualmente, agradezco a mis colegas y amigos Francisco Gallardo y María Paz Casanova por esos buenos momentos compartidos en el extremo sur. También, agradezco al laboratorio LABMEM de la Universidad Nacional de San Luis -San Luis, Argentina y a quien fuera nuestro gran anfitrión en San Luis, y hoy amigo, Dr. Luis Alberto Riveros. Finalmente, mis agradecimientos a los evaluadores por sus preciados comentarios y a Flavia Morello por la confección de la Figura 1.

5 Al respecto, hemos obtenido un nuevo Proyecto FONDECYT 1100354 (2010-2013), financiado por la Comisión Nacional de Investigación y Tecnología (CONICYT), llamado "Tecnología, función y significado del uso de colores en poblaciones arcaicas del extremo norte de Chile", el cual debiera permitirnos ahondar en estos aspectos. 


\section{BIBLIOGRAFÍA}

ALDENDERFER, M. 1990. Cronología y definición de fases arcaicas en Asana, sur del Perú. Chungara 24-25: 13-35.

ASCHERO, C. 1983-1985. Pinturas rupestres en asentamientos cazadores-recolectores. Dos casos de análisis aplicando difracción de Rayos X. Cuadernos del Instituto Nacional de Antropología 10: 291- 306.

ASCHERO, C. 1988. Pinturas rupestres, actividades y recursos naturales: un encuadre arqueológico. En: Arqueología contemporánea argentina. Actualidad y Perspectivas. Editores H. D. Yacobaccio, L. A. Borrero, L. C. García, G. Politis, C. Aschero, C. Bellelli, pp. 109-146. Ediciones Búsqueda, Buenos Aires.

ASCHERO, C. 1996. ¿Adónde van esos guanacos? En: Arqueología. Solo Patagonia. Ponencias de las II Jornadas de Arqueología de la Patagonia. Editor J. Gómez Otero, pp. 153-152. CENPAT-CONICET, Puerto Madryn, Argentina.

BARHAM, L. 1998. Possible early pigment use in South- Central Africa. Current Anthropology 39(5): 703-710.

BARHAM, L. 2002. Systematic pigment use in the middle pleistocene of South- Central Africa. Current Anthroplogy 43(1): 181- 190.

BATE, L. F. 1970 Primeras investigaciones sobre el arte rupestre de la Patagonia chilena. Anales del Instituto de la Patagonia 1: 15-25.

BATE, L. F. 1971 Primeras investigaciones sobre el arte rupestre de la Patagonia chilena (Segundo informe). Anales del Instituto de la Patagonia 2: 33-41.

BATE, L.F. 1974. Apuntes sobre la arqueología de los primeros poblamientos del extremo sur americano. Cuadernos de Trabajo 3; Instituto Nacional de Antropología e Historia, México.

BIRD, J. 1993. Viajes y arqueología en Chile Austral. Editor J. Hyslop. Ediciones Universidad de Magallanes, Punta Arenas, Chile.

BOSCHIN, M. T., A. SELDES, M. MAIER, R. CASAMIQUELA, R. LEDESMA y G. ABAD. 2002. Análisis de las fracciones inorgánica y orgánica de pinturas rupestres y pastas de sitios arqueológicos de la Patagonia Septentrional Argentina. Revista Zephyrus LV: 183-198.

CARDEN, N., L. MAGNIN y L. MIOTTI. 2009. Distribución de figuras animales y dinámica poblacional: un estudio comparativo en Patagonia (Provincia de Santa Cruz, Argentina). En: Crónicas sobre la piedra. Arte rupestre de Las Americas. Editores M. Sepúlveda, L. Briones y J. Chacama, pp. 119-128. Ediciones Universidad de Tarapacá, Arica.
CASAMIQUELA, R. 1984. El arte rupestre en la Patagonia. Editorial Siringa Libros. Neuquén, Argentina.

CASANOVA, M.P. 2006. Registro y diagnóstico de estado de preservación del arte rupestre, XII Región de Magallanes y Antártica Chilena. Informe inédito en posesión de la autora. MS

CASANOVA, M.P. 2007. Diagnóstico de estado de conservación de pinturas rupestres, Sector Pali Aike. Informe inédito en posesión de la autora. MS.

CENTRE TERRE. 2006. Última Patagonia 2006. http://www. centre-terre.fr/ultima2006/UltimaPatagonia_CRfevrier. PDF

CHRISTENSEN, M. 1997. Les colorants du site Bahía Colorada. En: Bahía Colorada (ile d'Englefield). Les premiers chasseurs de mammifères marins de Patagonie australe. Editor D. Legoupil, pp. 227-233. Editions Recherche sur les Civilisations, Paris.

CONRAD, N.J. 2005. An overview of the patterns of behavioural change in Africa and Eurasia during the Middle and Late Pleistocene. En: From Tools to Symbols. From Early Hominds to Modern Humans. Editores F. d'Errico y L. Backwell, pp. 294-332. Wits University Press, Johannesburg, Sudáfrica.

D'ERRICO, F., C. HENSHILWOOD, G. LAWSON, M. VANHAEREN, A.-M. TILLIER, M. SORESSI, F. BRESSON, B. MAUREILLE, A. NOWELL, J. LAKARRA, L. BACKWELL y M. JULIEN. 2003. Archaeological Evidence for the Emergence of Language, Symbolism, and Music-An Alternative Multidisciplinary Perspective. Journal of World Prehistory 17(1): 1-70.

D'ERRICO, F. y A. NOWELL. 2000. A New Look at the Berekhat Ram Figurine: Implications for the Origins of Symbolism. Cambridge Archaeological Journal 10(1):123-167.

FIORE, D. 2004. Pieles rojas en el confín del mundo. La valoración de las pinturas corporales en los registros histórico-etnográficos sobre aborígenes de Tierra del Fuego. Magallania 32: 29-52.

FIORE, D. 2005. Pinturas corporales en el fin del mundo. Una introducción al arte visual selk'nam y yamana. Chungara 37(2): 109-127.

FIORE, D. 2006. La manipulación de pinturas corporales como factor de división social en los pueblos selk'nam y yámana (Tierra del Fuego). Estudios Atacameños 31: 129-142.

FIORE, D. 2007. The economic side of rock art: concepts on the production of visual images. Rock Art Research 24 (2): 149-160.

FIORE, D., M. MAIER, S. D. PARERA, L. A. ORQUERA y E. L. PIANA. 2008. Chemical Analysis of the Earliest Pigments Residues from the Uttermost Part of the Planet 
(Beagle Channel Region, Tierra del Fuego, Southern South America). Journal of Archaeological Science 35: 3047-3056.

FIORE, D., M. MAIER, S. D. PARERA, V. RICHMOND, L.A. ORQUERA y E.L. PIANA. 2005. Los residuos de pintura más tempranos del confín del mundo: análisis de pigmentos de sitios arqueológicos del canal Beagle (Tierra del Fuego). En: Metodologías científicas aplicadas al estudio de bienes culturales. Editores A. Pifferetti y R. Bolmaro, pp. 194-200. Rosario, Argentina.

GAGE, J. 1999. Did colours signify? Symbolism in the red. Cambridge Archaeological Journal 9(1): 110-112.

GALLARDO, F. 2009. Sobre la composición y la disposición en el arte rupestre en Chile: consideraciones metodológicas. Magallania 37(1): 85-98.

GILLESPIE, J. D. 2007. Enculturing an Unknown World: Caches and Clovis Landscape Ideology. Canadian Journal of Archaeology 31: 171-189.

GRADIN, C. 2001. El Arte Rupestre de los cazadores de guanaco de la Patagonia. En: Historia Argentina Prehispánica 2. Editores E. Berberián y A. Nielsen, pp. 839-87. Editorial Brujas, Córdoba, Argentina.

GRADIN, C., C. ASCHERO y A.M. GUERRE. 1976. Investigaciones arqueológicas en la Cueva de las Manos, Estancia Alto Río Pinturas. Relaciones de la Sociedad Argentina de Antropología X: 201-250.

JAILLET, S., L.-H. FAGE, R. MAIRE y B. TOURTE. 2009. Découverte d'une grotte ornée dans l'archipel de Patagonie chilienne : la grotte du Pacifique. Colloque Archéologie Souterraine et Spéléologie. $41^{\circ}$ Congrès F.E.S. Mai 2006, Périgueux. Spelunca Mémoire 34 : 189.199.

JONES, A. y R. BRADLEY. 1999. The significance of colour in European Arcaheology. Cambridge Archaeological Journal 9(1): 112-114.

JONES, A. y G. MaCGREGOR (Editores). 2002. Colouring the past. The significance of colour in archaeological research. Editorial Berg, Oxford- New York.

LAMING- EMPERAIRE, A. 1966 Remarques sur l'art rupestre du Sud du Brésil. En: Actas y Memorias del XXXVII Congreso Internacional de Americanistas, Tomo 2: 495-503. Buenos Aires, Argentina.

LEGOUPIL, D. y A. PRIETO. 1991. Sepultura de niños canoeros en un abrigo pintado en Ultima Esperanza. Anales Instituto de la Patagonia, Sr. Cs. Hum. 20:133-138.

LEMONNIER, P. 1986 The study of material culture today: Toward an anthropology of technical system. Journal of Anthropological Archaeology 5: 147-186.

LEMONNIER, P. 1992. Elements for an Anthropology of Technology. Ann Arbor. Michigan.
LEWIS-WILLIAMS, 1995. Modelling the production and consumption of rock art. South African Archaeological Bulletin 50 : 143- 154.

MANSUR, M.E., A. LASA, y D. MAZZANTI. 2007. Análisis tecnofuncional de pigmentos provenientes de reparos rocosos de Tandilia: estudio arqueológico y experimental. En: Arqueología de las Pampas. Editores C. Bayón, A. Pupio, M.I. González, N. Flegenheimer y M. Frère, pp. 271-288. Universidad Nacional del Sur, Bahía Blanca, Argentina.

MANSUR, M.E., A. LASA y D. MAZZANTI. 2009. El uso de sustancias colorantes en el tratamiento de pieles. En: Actas del $2^{\circ}$ Congreso Argentino y $1^{\circ}$ Latinoamericano de Arqueometría, Vol. 1: 142-150. Editores O. Palacios, C. Vásquez, T. Palacios y E. Cabanillas. Buenos Aires, Argentina.

MANZI, L. 1991. Obtención, manufactura y usos de pinturas en grupos de cazadores- recolectores pedestres de la isla grande de Tierra del Fuego: un enfoque sistémico. En: El arte rupestre en la arqueología contemporánea. Editores M. M. Podestá, M. I. Hernández Llosas y Renard de Coquet pp. 139- 149. Buenos Aires, Argentina.

MARSHACK, A. 1981. On Paleolithic Ochre and the Early Uses of Color and Symbol. Current Anthropology Vol. 22 (2): 188- 191.

MASSONE, M. 1981 Arqueología de la región volcánica de Pali Aike (Patagonia meridional chilena). Anales del Instituto de la Patagonia 12: 95-124.

MASSONE, M. 1982 Nuevas investigaciones sobre el arte rupestre de Patagonia meridional chilena. Anales del Instituto de la Patagonia 13: 73-94.

MASSONE, M. 1985 Estudio comparativo de nuevos sitios con pinturas rupestres aborígenes de Magallanes. En: Simposio de Estudios de arte rupestre-Primeras jornadas de Arte y Arqueología-. Editores C. Aldunate, J. Berenguer y V. Castro 205-224. Museo chileno de Arte Precolombino, Santiago de Chile.

MENA, F. 1983. Excavaciones arqueológicas en Cueva Las Guanacas (RI-16). XI región de Aysén. Anales del Instituto de la Patagonia XIV: 65-75.

MENGHIN, O. 1952. Las pinturas rupestres de la Patagonia. RUNA 5: 5-22.

MENGHIN, O. 1957 Los estilos de arte rupestre de la Patagonia. Acta Prehistórica I: 57-87.

MENU, M. y P. WALTER. 1990. Les rythmes de l'art préhistorique. Techne 3: 11-23 ; C2RMF. Paris.

PAUNERO, R. 1992. Manos pintadas en negativo: un ensayo de experimentación. Revista de Estudios Regionales 
CEIDER 9: 47-68. http://rupestreweb.tripod.com/ manos.html

PETIT, J. y H. VALOT. 1991. Glossaire des peintures et vernis des substances naturelles et des matériaux synthétiques. Section Française de l'Institut International de Conservation, Association des Restaurateurs d'Art et d'Archéologie de Formation Universitaire and Institut Français de Restauration des CEuvres d'Art, Saint-Etienne, France.

PETRU, S. 2003. Red, black or white? The dawn of colour symbolism. Documenta Praehistorica XXXIII: 203-208.

PODESTÁ, M.M., R.S. PAUNERO y D. ROLANDI. 2005. El arte rupestre de argentina indígena. Patagonia. Academia Nacional de la Historia. GAC. Buenos Aires. PODESTÁ, M.M., C. BELLELLI, R. LABARCA, A.M. ALBORNOZ, A. VASINI y E. TROPEA. 2008. Arte rupestre en pasos cordilleranos del bosque andino patagónico (El Manso, región de los Lagos y Provincia de río Negro, Chile- Argentina). Magallania 36 (2): 143-153.

POPELKA- FILCOFF, R.S., J.D. ROBERTSON, M. GLASCOCK y CH. DESCANTES. 2007. Trace elements characterization of ochre from geological sources. Journal of Radioanalytical and Nuclear Chemistry 272 (1): 17-27.

SALAZAR, D., V. CASTRO, H. SALINAS y V.VARELA. 2010. Nuevas investigaciones sobre la prehistoria y la antigua minería de Taltal. Taltalia Vol. 2: 111-118.

SALAZAR, D., D. JACKSON, J.L. GUENDON, H. SALINAS, D. MORATA, V. FIGUEROA, G. MÁNRIQUEZ y V. CASTRO. 2011. Early evidence (ca. 12.000 BP) for Iron Oxide Mining on the Pacific coast of South America. Current Anthropology 52(3): 463-475.

SCHLANGER, N. 2004. "Suivres les gestes, éclats par éclats»- la chaîne opératoire d'André Leroi-Gourhan. Autour de l'homme: contexte et actualité d'André Leroi-Gourhan. Editores F. Audouze y N. Schlanger, pp. 5-25. Ediciones APDCA. Antibes, Francia

SEPÚLVEDA, M. 2009. Aspectos tecnológicos en la pintura. Reflexiones elaboradas a partir de análisis físico- químicos aplicados al estudio de las pinturas de la localidad del río Salado (II región, norte de Chile). En Crónicas sobre la piedra. Arte rupestre de Las Américas. Editores M. Sepúlveda, L. Briones y J. Chacama, pp. 119-128. Ediciones Universidad de Tarapacá, Arica.

SEPÚlVEDA, M., D. VALENZUELA y L. CORNEJO. 2011a. Óxidos de manganeso en el extremo norte de Chile: en torno al abastecimiento, movilidad y producción del color negro durante el período arcaico. Trabajo presentado en Primera Reunión de Internacional sobre Minería Prehispánica en América. San Pedro de Atacama, Chile. Manuscrito inédito en posesión de las autoras.
SEPÚlVEDA, M., M. GARCÍA, C. CARRASCO y C. SANTORO. 2011b. Contextos arqueológicos y pinturas rupestres de la precordillera de Arica (extremo norte de Chile). Manuscrito inédito en posesión de los autores.

SEPÚLVEDA, M. y E. LAVAL. 2010. Aplicación y aplicabilidad de métodos físico- químicos para el estudio de las pinturas rupestres. Ejemplo de estudio en la localidad del río Salado (II región, norte de Chile). Actas del XVII Congreso Nacional de Arqueología Chilena 2006, Tomo II: 825-834, Valdivia.

SEPÚlVEDA, M., E. LAVAL, L. CORNEJO y J. ACARAPI. 2012. Elemental characterization of prehispanic rock art and arsenic in northern Chile. Rock Art Research 49(1). En prensa.

SERNAGEOMIN. 2003. Mapa geológico de Chile: Versión Digital. Publicación Geológica Digital n4. CD-ROM, versión 1.0. Base Geológica escala 1:1.000.000. http:// www.ipgp.fr/ dechabal/Geol-millon.pdf

SIRACUSANO, G. 2008. El poder de los colores. De lo material a lo simbólico en las prácticas culturales andinas. Siglos XVI-XVIII. Fondo de Cultura Económica, Buenos Aires.

SPADES, S. y J. RUSS. 2005. GC-MS analysis of lipids in prehistoric rock paints and associated oxalate coatings from the lower Pecos Region, Texas. Archaeometry 47: 115-126.

STAFFORD, M.D., G.C.FRISON, D. STANFORD y G. ZEIMANS. 2003. Digging for the Color of Life: Paleoindian Red Ochre Mining at the Powars II Site, Platte County, Wyoming, U.S.A. Geoarchaeology: An International Journal 18 (1): 71-90

TAÇON, P. 1999. All Things Bright and Beautiful: the Role and Meaning of Colour in Human Development. Cambridge Archaeological Journal 9(1): 120-123.

VANHAEREN, M. 2005. Speaking with vedas: The evolutionary significance of personal ornaments. En: From Tools to Symbols. From Early Hominds to Modern Humans. Editores F. d'Errico y L. Backwell, pp. 525-553. Wits University Press, Johannesburg, Sudáfrica.

VILHENA, V., H. BADU, F. D'ERRICO y D. VIALOU. 1996. Les colorants rouges de l'habitat rupestre de Santa Elina, Mato Grosso (Brésil). Techne 3: 91-97.

WAINWRIGHT, I., K. HELWIG, D. ROLANDI, C. ASCHERO, C. GRADIN, M.M. PODESTÁ, M. ONETTO y C. BELLELLI. 2000. Identification of pigments from rock painting sites in Argentina. En: L'art avant la préhistoire. La conservation de l'art préhistorique. 10es journées d'études de la Section Française de l'Institut Nacional de Conservation. Editores por R. Hocquette, M. Stefanaggi, P. Vierte y J. Brunet, pp. 15-24. Champs Sur Marne, Francia. 
WAINWRIGHT, I., K. HELWIG, M.M. PODESTÁ y C. BELLELLI. 2000. Analysis of pigments from rock painting sites in Río Negro y Chubut Provinces. En: Arte en las rocas. Arte Rupestre menhires y piedras de colores en Argentina. Editores M.M. Podestá y M. de Hoyos, pp. 203-206. Buenos aires, Argentina.

WATCHMAN, A. 1990. A summary of occurrences of oxalaterich crusts in Australia, Rock Art Research, 7: 44-50.

WATCHMAN, A., B. DAVID, I.J. Mc NIVEN y J.M. FLOOD. 2000. Micro-archaeology of Engraved and Painted Rock Surface Crusts at Yiwarlarlay (the Lightning Brothers site), Northern Territory, Australia. Journal of Archaeological Science 27: 315-315.
WHALLON, R. 2006. Social networks and information: Non"utilitarian" mobility among hunter- gatherers. Journal of Anthropological Archaeology 25: 259-270.

WHITE, R. 1996. Actes de substance : de la matière au sens dans la représentation paléolithique. Techne 3 : 29-28; C2RMF. Paris.

WHITLEY, D. 2005. Introduction to rock art. Left Coast Press, California.

WRESCHNER, E. 1980. Red ochre and human evolution: a case for discussion. Current Anthropology 21(5): 631- 644.

YACOBACCIO, H., M.P. CATÁ, M.P., P. SOLÁ y M.S. ALONSO. 2008. Estudio arqueológico y físico-químico de pinturas rupestres en Hornillos 2 (Puna de Jujuy). Estudios Atacameños 36: 5-28. 